whatever. He records that all the fibres going to the occipital convolutions were non-medullated. We have found a similar imperfection in the medullation, but are not sure whether this is due to the age of the animal or to the abnormality.

On the contrary all observers are agreed that in old longstanding cases of blindness there are always to be found changes in the mid-brain centres and in the area striata. There would seem to be little doubt that in reaction at a distance the time factor is the important one. This may explain some of the discrepant results obtained in the cortical investigations of tabes and amputations.

\title{
REFERENCES
}

Warrington.- " On the structural alterations observed in nerve cells." $J l$, of Physiol., Vol. XXIII, 1898.

Leonowa. - "Ueber das Verhalten der Neuroblasten des Occipitallappens bei Anophthalmus und Bulbusatrophie und seine Beziehungen zum Sehact." Arch.f. Anat. und Entwickelung, 1893.

Bolton. - "Exact histological localisation of the visual area of the human cerebral cortex." Phil. Trans. of the Roy. Soc., Series B, Vol. CXCIII, 1900.

Schwalbe.- "Die Morphologie. der Missbildungen des Menschen und der Tiere," Jena, 1906.

Durlacher.-Deutsch. Med. Wochensch., Jahr. 35, pp. 1659-61. Durlacher quotes the findings of many others such as Haab and Spiller.

Black. - "The central nervous system in a case of cyclopia in man." $J l$. of Comp. Neur., Vol. XXIII, 1913.

Monakow.- "Die Lokalisation im Grosshirn." Wiesbaden, J. F. Bergmann, 1914.

Campbell.- " Histological Studies on the localisation of cerebral functions." Cambridge Univ. Press, 1905.

Buzzard and Greenfield.- " Pathology of the nervous system." London, 1921.

Parsons, Sir John. - Pathology of the Eye, Vol. IV, p. 1409.

\section{THE RESULT OF TREATMENT BY ARTIFICIAL LIGHT ON PHLYCTENULAR AND OTHER TUBERCULOUS LESIONS OF THE EYE*}

\section{By}

\author{
A. B. NutT, M.B., M.Sc. \\ SHEFFIELD
}

MUCH attention has been paid recently to the action of light upon the body, and although its mode of action is not known, yet, on empirical grounds, it is being used extensively as a form of treatment in disease. We know that life is dependent upon the radiant energy from the sun, and recently it has been shown that the rays of short wave length have a profoundly beneficial effect on the growth and maintenance of the human body.

* Read before the North of England Ophthalmological Society, March 6, 1925. 
The method of treatment by artificial light as practised by Finsen, for lupus, was to expose small patches of the lesion to the rays of the carbon-arc lamp, and by this means he obtained very gratifying results; but he noticed that not only did the patches exposed improve, but other patches not exposed to the rays did likewise; this observation led to the treatment of other tuberculous lesions by exposure of large areas of the body to the sun's rays, and also, in climates where sunshine is not obtainable, to the rays of the carbon-arc and mercury vapour quartz lamp, both of which are rich in the rays of a wave length less than $300 \mu \mu$

Such exposure to the ultra-violet rays is being employed widely in many branches of medicine and surgery, in cases of lupus and psoriasis, in tuberculous lesions of bone, as at Leysin, Alton, and elsewhere, as well as in other types of tuberculous infection.

Further, during the last five years, remarkable advances have been made in the treatment of rickets, in that it was discovered that the disease could be cured by means of exposure to the mercury vapour quartz lamp (Huldchinsky, 1919-20), and also, that the onset of xerophthalmia in rats was very materially delayed by it. It was therefore natural that in cases of phlyctenules, which are admittedly more prevalent in people of strumous diathesis, living in bad surroundings, where sun is scarce, and food containing adequate vitamine scarcer, treatment by artificial light should be tried. It is now definitely known that ultra-violet radiation cannot actually take the place of vitamines, but if small quantities are present in the body, the exposure will mobilize them for use so that growth continues or the rickety condition ceases, as the case may be. Therefore, in applying such treatment it is essential that vitamine be supplied. This has been done in the form of cod-liver oil emulsion with hypophosphites.

Intractable phlyctenular conditions were treated, in years gone by, by local applications, with attention to regulation of the bowels and to tonics for the general health. Later, fats were given empirically, even cod-liver oil, as advised by Soelberg Wells in his text-book, published in 1870 ; the open air too seems to have been appreciated as beneficial, but why, was not understood.

Quoting from Wells : "Nothing is so injurious as to confine the patient to the dark on account of the photophobia, for in this way the eye will become so sensitive that no light will be borne," and further on, under phlyctenular corneitis, he advises visits to the seaside with sea bathing.

It was noticed at the Alexandra Hospital for diseases of the hip, that when the patients were moved into the open air, there was a decrease in the number and severity of the phlyctenules; it was found also that cases did better when removed to a 
sanatorium, and more recently, exposure to the sun, particularly in Switzerland, has proved to be still more efficacious.

The typical picture of many cases of phlyctenules with their frequent relapses and intractableness to treatment is well known. The patients treated by exposure to the mercury vapour lamp in every case show marked improvement; the stoop in their attitude begins to disappear, they become generally more robust and their appetites improve. The child who comes under treatment weak and anamic, irritable, crying whenever touched, burying its head in its mother's lap, soon becomes happier and stronger, and the appetite improves. The blepharospasm and lacrymation disappear, the skin looks healthier, and the older ones will tell you without any questioning that they are feeling better in themselves and that their eyes have been more comfortable since they started to have "sunshine." The phlyctens clear up gradually; in some cases relapses occur, but they are not so frequent after lamp treatment as they were before. In some cases the eyes remain quite quiet, and generally speaking, as is shown by the cases quoted,they remain quiet in all weathers, and at work or at school,while having the exposure; but if the treatment is stopped as soon as the eye is quiet, the condition tends to return and the patient goes back. In the older cases with such conditions as phlyctenular pannus and sclerosing keratitis, the eyes have quieted as they never did previously, and have become much less painful than before treatment, whilst vision has become clearer.

The routine of treatment has been as follows :

The patients strip and are exposed to the rays back and front ; there is a nurse in charge who times the exposures, which, commencing with ten minutes per day for the first few days, are gradually increased to one hour per day. The eyes are protected by wearing London-smoke glasses; the room, of course, is suitably heated. Several patients are exposed at once. (The lamp used is supplied by Quartz I ampen-Gesellschaft M.B.H., Hanat.) The usual general and local treatment is emploved, together with codliver oil.

The cases which have been treated fall under two headings :

(1) The chronic cases that have been under treatment for a long period previously, with little, if any, improvement.

(2) The recent cases treated as soon as they have appeared at the Out-Patient Department.

The first group comprise cases with histories extending.from five months to four years before treatment with the ultra-violet rays was commenced. The value of these exposures in treatment can be best shown by a summary of some of the cases. 
(1) Male, aged 35 years, Wassermann reaction negative. His right eye began to trouble him in February, 1923 ; he was first seen May 2, 1924, when he had a definite sclerosing keratitis; the cornea was hazy, the eye very red with well marked circumcorneal injection; the pupil was distorted and the iris muddy. Vision : hand movements only. He was treated with local applications, tonics and tuberculin (from which he got a severe re-action) until September 9, 1924, when sunlight treatment was commenced.

On that date vision was hand movements only, the eye was still as painful and injected as ever, and he asked to have it removed. When seen fourteen days later improvement had already commenced.

October 27 the cornea was clearer, there was no injection to be seen, and he volunteered the information that he could discern window frames, trees, and details of objects, and that his eye had never been so comfortable since it became bad.

December 29,1924 , tuberculin was stopped; he was seen regularly up to January 27 without any relapse; on that date vision was $6 / 36$ under suitable conditions; the eye was quiet in spite of the fact that he had had a severe attack of bronchitis and been confined to bed for a week at the beginning of January.

On February 27 he had a slight localized injection on the inner side of the limbus; this was attributed to the use of dionin drops the strength of which had recently been increased to 4 per cent. from 2 per cent. The injection remained until March 4 when the drops were stopped. He had cod-liver oil emulsion throughout.

(2) Male, aged 16 years. First seen November 3, 1920. Vision : R. nil ; L. 6/60. He had superficial ulceration of the cornea; there was no trachoma present. Later trachoma with pannus developed, and on July 7,1922 , he had a bad relapse this time in the left eye. On April 13, 1924, a note was made that he still kept on having relapses in spite of very energetic treatment as an in-patient for fourteen weeks.

Treatment was continued with local applications, tonics, and tuberculin, with no improvement, up to September 9, 1924, when he had a mixed pannus above, and lamp treatment was suggested.

December 19 he stated that he felt better and his eyes were quieter; there was less photophobia.

January 5 the eyes were quieter, the corneae were still hazy in the upper part and vascular, but they felt easier and photophobia was markedly less.

March 4, 1925, he stated that the eye had never been so quiet since treatment was commenced four years previously. Vision : R. 6/18; L. nil. Of course a great deal of permanent damage had been done to the eyes before lamp treatment was commenced, but they are more comfortable, and what vision there is, is better than before the treatment and the patient is more robust and happier.

(3) Male, aged 49 years. First seen February 3, 1922. Vision : R. and L. 6/6. He had marginal ulcers on the left cornea with peripheral scarring; there was some pigment on the lens, no keratic precipitates; fundus normal. He gave a family history of one sister dying from tuberculosis. He had frequent relapses with the appearance of fresh ulcers at the margin of the cornea; there was persistent circum-corneal injection with vascular ulceration, practically all round the corneal margin, and in June, 1924, he had an attack of iritis. The condition persisted and he was put on lamp treatment in September, 1924. He had been treated previously with local applications, tonics, and tuberculin.

Tuberculin was stopped on October 20, since then he has progressed very slowly, but getting definitely better all the time. The lamp exposures were discontinued for a time, and later recommenced at the patient's request.

February 27, 1925, the injection was much less, there was no photophobia and the eye was comfortable. There were two small raised patches still remaining at the margin, with vessels running into them.

(4) Male, aged 6 years, Wassermann reaction negative. The eye condition commenced June, 1923, but he was not seen here until October, 1923, since when he has been an in-patient here or at the Convalescent Home. He was seen at the Home at the end of last September. His condition was then serious, he was anaemic, weak, apathetic, and with no appetite at all; he lay quite still from morning till night, and to look at him he appeared simply skin and bone. $\mathrm{He}$ had periodic attacks of vomiting, with a distended abdomen. He was covered from head to foot with papular necrotic tuberculous sores, while on his feet there were, and, as a matter of fact,' still are, typical tuberculous ulcers. There were bad phlyctenular ulcers over the centre of the right cornea; the eye was very injected, the lids were 
red and swollen, with a bad ciliary blepharitis : his nose and the angle of his mouth were sore; everyone expected him to die.

October 20, 1924, he was put on to exposures with the mercury vapour lamp and slowly began to improve.

November 7 he had a fresh crop of phlyctens all round the corneal margin; these cleared up and his eye became quite quiet: it has remained so.

His general condition has improved enormously; practically all the skin condition is healed, the vomiting has ceased, his weight has increased; he can walk about and will play with other children.

(5) Female, aged 43 years. First seen November, 1921. She had iritis with an old interstitial keratitis in both eyes; that apparently settled.

September 15, 1922, she appeared with fresh ulceration at the corneal margin below. Tuberculin was used but not attended by much success; the eye remained red and painful. Two months ago she was put on lamp treatment and is now more comfortable, while the eye is quiet, the red patches having cleared up and the ulcers healed.

The report on these five cases must suffice as an indication of the result of treatment of old standing tuberculous and phlyctenular conditions by ultra-violet rays. In the first there was a sclerosing keratitis; in the second, pannus; in the third and fifth, persistent marginal ulceration; and in the fourth, a strumous keratitis, accompanied by general debility and an obvious tuberculous skin condition-a fairly good selection of cases.

Fresh Cases.-The treatment of early cases of phlyctenules has yielded so far quite encouraging results; the following are typical cases :

(6) Female, aged 33 years. First seen October 10, 1924. Vision : R. 6/9; L. 6/24. There were large phlyctenular nodules at the limbus on the left eye, with very marked circum-corneal and conjunctival injection. She gave a history of tuberculous glands in the groin and neck, the latter having been operated upon two years ago. She was put at once on to lamp treatment.

October 27, the eye was better but fresh nodules had formed. The exposures, together with cod-liver oil, were continued, in spite of which fresh phlyctens appeared in the right eye, the left being practically clear. The lamp was stopped for one month; at the end of this time, December 22, the right eye was quiet, but the left was worse than ever; she was treated again with the ultra-violet rays, and when seen on January 5 both eyes were quiet, and she stated that she felt better in herself and her eyes were more comfortable while she was having that treatment. Since then her eyes have both been perfectly quiet, and she insists that she is much better while having the treatment and wants to go on with it. Vision : R. and L. 6/6.

(7) Female, aged 14 years. First seen December 12, 1924. Vision : R. 6/6; L. 6/24. She had phlyctenular pannus in the left eye; the eye was very painful and red, with marked blepharospasm; she was put on to tuberculin and lamp treatment. One month later she developed two phlyctens on the margin of the right cornea, but the left eye was less painful and less injected, though the pannus was still present to some extent. One month later there was still some injection in the right, but no definite phlyctens, while the left showed only a few vessels invading the cornea at the margin. She was seen March 2 , when both eyes were perfectly quiet. Vision : R. and L. 6/6.

(8) Female, aged 16 years. First seen August 26, 1924. Vision : R. and L. 6/18. She had phlyctenular marginal ulcers in both eyes; both were painful and injected with profuse lacrymation. She was at once started with tuberculin and lamp treatment, together with cod-liver oil.

October 27 the photophobia had disappeared and both eyes were clear with the exception of a little injection below in the left.

November 9 sunlight treatment was stopped.

November 18 she had a definite phlycten in the left eye with photophobia and a week later one developed in the right eye. 
January 5 both eyes were quiet, she looked pale and suggested that she felt better while having the exposures to mercury vapour lamp, and that it had helped to clear her eyes up. Vision : R. and L. 6/6.

January 26 the right eye became injected below and on February 10 there was a definite fresh crop of phlyctens present. The sunshine was recommenced and by the end of February both eyes were quite clear.

(9) Male, aged 7 years. First seen January 20, 1925.

Phlyctenules almost all round the limbus of the right eye. There was marked photophobia and lacrymation, the lids were sore, the globe and circum-corneal zone were injected. The left eye was quiet, the nose and outer angle of the right eye were sore. He was exposed to the mercury lamp daily.

On February 2 there remained one large phlycten astride the limbus below, while the injection was still present.

February 18 the eye was perfectly clear and a facetted scar was present astride the limbus at about five o'clock.

February 21 the light treatment was discontinued. So far there has been no relapse; although he was a bad case; the condition completely cleared up in just four weeks.

(10) Male, aged 16 years. First seen November 5, 1924.

There was superficial vascular ulceration of the cornea at the margin. The circum-corneal zone was markedly injected; conjunctiva was engorged and chemosed; the pupil was small and irregular, re-acted sluggishly to light, and the iris was muddy. He was treated with local applications; cleared up and was discharged.

December 4 he returned with a strumous ulcer just outside the centre of the right cornea, a leash of vessels running into it. It became worse and he had to be re-admitted; he then had bright circum-corneal injection and the iris was vascular; there was much pain and photophobia. He was at once put on to lamp treatment together with cod-liver oil emulsion, in addition of course to local treatment. The eye cleared very quickly, and he had been discharged for only a week or so when his left eye flared up with strumous ulcer at about the centre of the cornea. The treatment was continued and both eyes were quiet by February 27.

March 4 both eyes quiet; he is sunburnt and looks the picture of health; there are two corneal scars remaining.

(11) Female, aged 15 years. First seen February 10, 1925.

Phlyctenules on the outer side of both eyes. She was put at once on tuberculin and lamp treatment; there was a very violent reaction to the tuberculin.

February 16 the phlyctens were still present, the eyes very red, there was blepharospasm and lacrymation. The treatment was continued daily and both eyes were perfectly clear by March 2 .

These cases are taken from thirty cases which have been treated by exposure to the rays of the mercury vapour quartz lamp and are still being observed.

As far as can be seen at present, the benefit to the body as a whole, produced by exposure to the ultra-violet rays, re-acts upon the tuberculous and strumous conditions met with in the eye, for good, and such exposure will take the place of sanatorium and open-air treatment, the benefit of which seems to be due very largely to the effect of the spectral rays of short wave length.

The ordinary hospital patient cannot afford the time or the money for sanatorium treatment, and it is possible by means of the mercury vapour quartz lamp which is very rich in ultra-violet rays, to give patients the effect of sun treatment in a town-where the ultra-violet rays are cut off very effectively by a smoke screenand with very little loss of time.

The results of the cases treated here seem sufficiently encouraging to warrant their publication, so that others may try treatment 
along similar lines and more definite conclusions may be arrived at as to whether or not the ultra-violet rays are to be a permanent addition to our armamentarium in the treatment of phlyctenular and other tuberculous conditions.

This series of experiments was commenced in August, 1924, on a few selected cases, and since then, the number of cases has been increased; but as there is only one mercury vapour lamp in use in the Sheffield Infirmary, the number of cases treated has necessarily been limited. As far as possible the cases most intractable to treatment on ordinary lines have been chosen for this work. If the results continue to be as satisfactory as they are at present a much wider application of this method of treatment will be adopted, $c . g$., probably a great majority of corneal ulcers will be treated in this manner.

I propose, at Mr. Pooley's suggestion, to continue this series of experiments and to extend the range of investigation to other non-tuberculous lesions.

I have carried out these observations by the kind permission of Mr. Pooley, on his cases, and I should like to thank him very much indeed for his genernus assistance and support in this work.

\title{
A SLIT-LAMP
}

IBY

\author{
M. S. MAYOU \\ LONDON
}

THIs instrument is designed to obviate some of the disadvantages attached to the ordinary Zeiss slit-lamp. One of the chief objects attained is the rapidity with which routine examination can be made with the instrument.

(1) When once the lamp is in focus no further adjustments need be made for the examination of any number of patients, and consequently the average examination does not require more than about one minute.

(2) The lamp and microscope move in unison so that one adjustment does for both focussing the image and directing the light.

(3) The instrument is portable and can be used on any small table with a glass top, and when not in use can be put out of the way.

(4) The slit can more accurately be focussed on any portion of the anterior part of eye. 